\title{
Nucleic acid detection using a universal electrochemical sensor for SNS differentiation
}

\section{Detección de ácidos nucleicos usando un sensor electroquímico universal para la discriminación de SNS}

\author{
Percy Calvo-Marzal ${ }^{1}$, Dmitry M. Kolpashchikov ${ }^{1,2,3}$ and Karin Y. Chumbimuni-Torres ${ }^{1}$ \\ ${ }^{1}$ Department of Chemistry, University of Central Florida, 4000 Central Florida Blvd., Orlando, FL 32816 \\ ${ }^{2}$ National Center for Forensic Science, University of Central Florida, Orlando, FL 32816 \\ ${ }^{3}$ Burnett School of Biomedical Science, University of Central Florida, Orlando, FL 32816
}

Recibido el 26 de diciembre del 2017, aceptado el 31 de diciembre del 2017

DOI: https://doi.org/10.33017/RevECIPeru2017.0008/

\begin{abstract}
Nucleic acid detection with high sensitivity and selectivity capabilities could aid in the diagnosis of varies diseases such as: infections, cancer, among others. Discrimination of a mismatch or single nucleotide substitution (SNS) is challenge due to a minimum pair to pair formation double strand needed to stabilize the structure. Here we present a new approach to atinge the needed stability by using additional segments strains to favored stabilization. The use of additional complementary strains facilitates the discrimination of a SNS in a cooperative way.
\end{abstract}

Keywords: Nuclei acid, Single nucleotide substitution, infection, cancer

\section{Introduction}

The World Health Organization (WHO) identifies infectious diseases as a major global health issue. [1-3]. This continued threat is due to the emergence of new diseases and antibiotic resistant bacteria and the rapid dissemination of these diseases due to overpopulation and globalization.[4]

To address these threats, fast, affordable, and reliable diagnostic tools are needed. Detection of single nucleotide substitutions (SNS) can differentiate between pathogenic and nonpathogenic bacteria. Pathogenic E. coli strainsO157:H7 exhibit 99\% genome identity to nonpathogenic K12 strains. Nucleotide alignments reveal that 16S rRNA sequences have 9 SNS between the two strains.

State-of-the-art sensors for nucleic acid detection fail to detect these SNS, especially at ambient temperatures and when buried in the secondary (folded) structure that is characteristic of ribosomal RNA (rRNA) [5-7]. Nucleic acid amplification tests (NAATs) offer high sensitivity and rapid results [810] but they are prone to contamination, frequently produce false-positive results and require technical expertise.

Here, we propose to develop a point-of-care (POC) platform based on a self-assembling binary DNA approach $[11,12]$. Two hybrid intermediary strands will be designed such that half of each strand is complementary to the target nucleic acid and the other half complementary to a universal DNA probe that is immobilized on a solid surface. Self-assembly of these components along with the target rRNA will result in formation of a $4 \mathrm{~J}$ structure. A redox marker covalently attached to an intermediary strand allow formation of the $4 \mathrm{~J}$ structure to be monitored by electrochemical detection (4J E-biosensor). 
The ideal POC sensor for bacterial pathogens will exhibit a signal in the presence of pathogenic bacteria and distinguish between closely related, non-pathogenic species. Binary probes exhibit excellent selectivity and can differentiate SNS in DNA strands [13-15]. We will use the high selectivity of binary probes to solve the challenging task of differentiating between two E. coli strains-O157:H7 and K12. Sequences of $16 \mathrm{~S}$ and $23 \mathrm{~S}$ rRNA from these two strains are $99 \%$ identical. The alignment data show that the $16 \mathrm{~S}$ and 23S rRNA only exhibit 9 and 15 SNS between the two strains, respectively. There are 2 SNS clusters containing either two or three nucleotide variations in $23 \mathrm{~S}$ rRNA, providing target regions to differentiate between the two strains [16].

Recent work by the $\mathrm{PI}$ and $\mathrm{CoPI}$ has demonstrated for the first time a single probe that universally recognizes DNA and RNA, differentiates between SNS at room temperature and uses an electrochemical transducer. The platform was adapted from the $4 \mathrm{~J}$ molecular beacon approach proposed and investigated by the CoPI. This platform utilizes a hairpin DNA stem-and-loop (SL) probe attached to a gold electrode through a thiol bond (Fig. 1). Two adaptor strands, $m$ and $f$, are introduced during hybridization. The $\mathrm{m}$-strand is covalently bound to an electrochemical redox marker, methylene blue (MeB). The DNA-SL probe is stable in its hairpin conformation in the absence or presence of the target and hybridizes to form a $4 \mathrm{~J}$ architecture only when the adaptor strands are present. The electrochemical signal is generated by the electron transfer (eT) between the MeB redox marker on the m-strand and the electrode's surface.

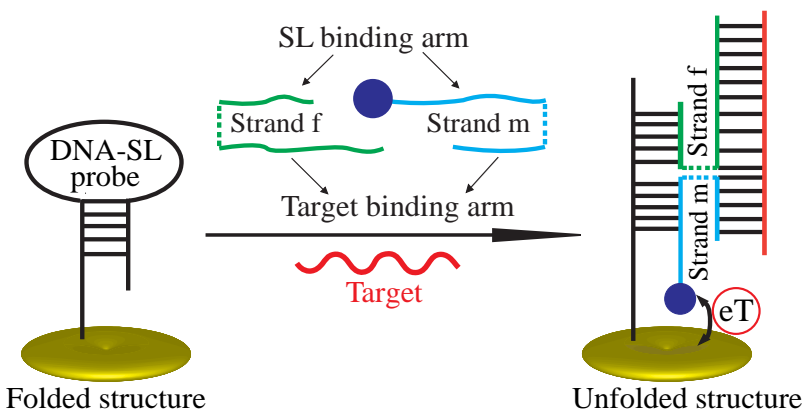

Figura 1: Schematic of the $4 \mathrm{~J}$ E-biosensor for RNA/DNA detection.

Electrochemical methods combined with highly selective recognition elements can revolutionize real-time and on-site biosensing applications towards POC. Hairpin DNA probes, which consist of a SL structure, offer high selectivity when compared to their corresponding linear probes [17], allowing for the distinction between targets that differ by a SNS $[18,19]$. Kramer et al. introduced a molecular beacon approach [20], which optically monitored a hairpin DNA probe containing a fluorophore on one end and a quencher on the other end (Fig. 2A). Fan et al. [21] adapted this approach for electrochemically detection by replacing the fluorophore with a redox marker (electroactive reporter), ferrocene, while covalently attaching the probe's other end to a gold electrode via a thiol bond (Fig. 2B). In this configuration, the electroactive species is near the electrode, facilitating a high rate of eT. Upon hybridization, the distance between the electroactive species and the electrode greatly increases, resulting in a low eT rate (signal decrease).
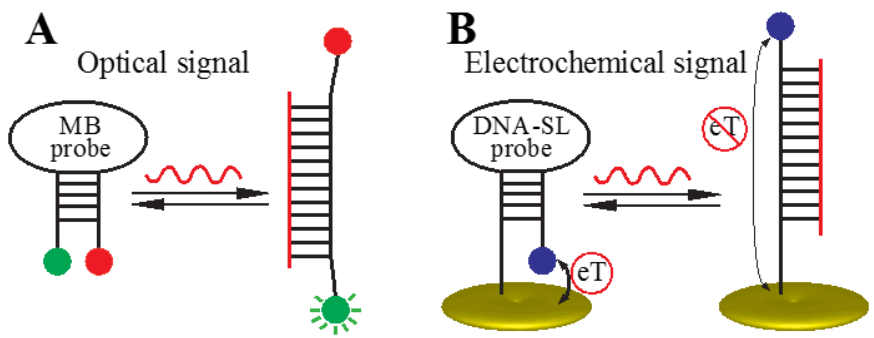

Figure 2: A) Schematic diagram of molecular beacon (MB) and B) E-DNA biosensor.

The seminal work of Fan et al. [21] opened the door to SNS differentiation using hairpin DNA-SL probes with electrochemical transducers. Although SNS differentiation was possible using this approach, the electrochemical sensor operated as a signal OFF upon hybridization. The primary drawbacks of the signal OFF sensing platform include i) false positive responses caused by interactions other than the target binding $[21,24]$ and ii) limited signal since the original signal current can only be suppressed up to $100 \%$, upon hybridization with the target.

These limitations could be addressed by designing a signal $O N$ sensing platform. Different approaches were proposed for signal $O N$, including the use of DNA-PEG-DNA triblock macromolecule [25], a target-induced strand displacement mechanism [26] and sensors based on hairpin DNA-SL probes [2730]. However, these signal ON sensing platforms produce a nonzero background signal in the absence of the target. Since the redox marker could be in sufficient proximity to the electrode. In contrast, the proposed $4 \mathrm{~J}$ architecture integrated onto an electrode displays zero background signal, since the hairpin DNA-SL probe does not contain a redox marker. Instead, the electroactive species is covalently bound to the end of one adaptor strand. The eT is observed only upon hybridization to form 
the $4 \mathrm{~J}$ architecture, offering a signal $\mathrm{ON}$ sensing platform with zero background signal.

Targets that form stable secondary structures are unlikely to hybridize with the DNA-SL probe because unfolding both the target and the probe is thermodynamically unfavorable [5-7, 31]. The $4 \boldsymbol{J}$ system approach proposed here will address this challenge by using two intermediaries adaptor strands, resulting in a thermodynamically favorable hybridization between the hairpin DNA-SL probe and the folded target (Fig. 3B). Detection of the folded target is possible due to the presence of the intermediary adaptor strands that aid in opening the hairpin DNASL probe and the folded target as studied by the PI and the CoPI (accepted manuscript for publication). Consequently, the $4 \mathrm{~J}$ E-biosensor can detect both folded and unfolded targets, increasing the applications of this system.

The proposed fundamental study of the $4 \mathrm{~J}$ system approach is necessary to engineer a POC device for differentiation of SNS in folded and unfolded nucleic acids. Such a device could present valuable applications in environmental, food safety, clinical diagnostics, and national defense [32-34]. There is a particular interest to detect rRNA to aid in diagnosing bacterial infections. The $\mathrm{WHO}$ report that about five million people die annually from lower respiratory infections, diarrheal diseases and tuberculosis [1]. A variety of techniques for rRNA detection have been reported, such as northern blotting [35-38], PCR [39-43], and fluorescence [4446]. However, these methods are prone to contamination, require skilled personnel, and lack the portability necessary for POC diagnostics [47]. Electrochemical methods have been recently explored as an alternative approach [24,30, 48-51] since they have greater potential for on-site testing while offering fast, simple, portable and inexpensive detection [52-54].

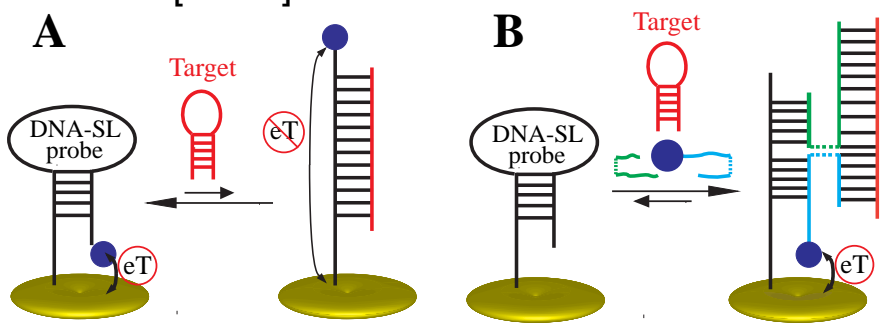

Figure 3: Schematic representation of hairpin DNA$S L$ probe hybridize to folded targets. A) Duplex hybrid and B) $4 \mathrm{~J}$ system.

\section{Results}

Sequence descriptions can be found in Table 1.

Table 1: Nucleic acid sequences used for 4J E-biosensor design and analysis.

\begin{tabular}{|c|c|c|}
\hline $\begin{array}{l}\text { Synthetic } \\
\text { oligonucleotide }\end{array}$ & Abbreviation & Sequence \\
\hline DNA stem loop probe & $\begin{array}{l}\text { DNA-SL } \\
\text { probe }\end{array}$ & $\begin{array}{l}\text { 5'S-S- }\left(\mathrm{CH}_{2}\right)_{6} \text {-TTT-TTT-TTT-TCGC-GTT-AAC-ATA- } \\
\text { CAA-TAG-ATC-GCG-3' }\end{array}$ \\
\hline Adaptor strand m & $\begin{array}{l}\text { m-GCG-MeB } \\
\text { m-3T-MeB } \\
\text { m-10T-MeB }\end{array}$ & $\begin{array}{l}\text { 5'-CAA-ACA-CCA-T-TAT-GTT-AAC-GCG-MeB-3' } \\
\text { 5'-CAA-ACA-CCA-T-TAT-GTT-AAC-TTT-MeB-3' } \\
\text { 5'-CAA-ACA-CCA-T-TAT-GTT-AAC-TTT-TTT-TTT- } \\
\text { T-MeB-3' }\end{array}$ \\
\hline Adaptor strand f & f1 & $\begin{array}{l}\text { 5'-GAT-CTA-TTG-TGT-CAC-ACT-CCA-3' } \\
\text { 5'-GAT-CTA-TTG-ATC-CGT-ATC-CAG-3' }\end{array}$ \\
\hline Target & $\begin{array}{l}\text { miRNA-122 } \\
\text { T-DNA }\end{array}$ & $\begin{array}{l}\text { 5'-UGG-AGU-GUG-ACA-AUG-GUG-UUU-G-3' } \\
\text { 5'-CTG-GAT-ACG-GAT-ATG-GTG-TTT-G-3' }\end{array}$ \\
\hline $\begin{array}{l}\text { Single nucleotide } \\
\text { substitution }\end{array}$ & SNS & 5'-UGG-AGU-GUG-ACA-AUG-GU $\underline{C}-U U U-G-3 '$ \\
\hline
\end{tabular}

Computational modeling was used to design the sequence of the $m$ intermediary adaptor strand by studying different nucleic sequences. The $m$ adaptor strand (m-GCG-MeB) was designed to anchor the MeB near the surface of the gold electrode after $4 \mathrm{~J}$ formation. Results obtained from computational modeling showed that m-GCG-MeB will hybridize with the DNA-SL probe in the absence of the $f$ adaptor strand and the target. Consequently, a false positive electrochemical signal was observed (Fig. $5 A-b)$ due to the energetically favored hybridization between the complementary base pairs and the DNA-SL probe. The revised sequence of the $m$ adaptor strand replaced guanine-cytosine-guanine (GCG) with thymine-thymine-thymine (TTT) at the 3' end to eliminate the unwanted interaction between the $\mathrm{m}$ adaptor strand and the DNA-SL probe. Thus, a false positive electrochemical response in the 
absence of the target was not observed (Fig. 4B-b), indicating that $\mathrm{m}-3 \mathrm{~T}-\mathrm{MeB}$ did not bind to the DNASL probe by itself.
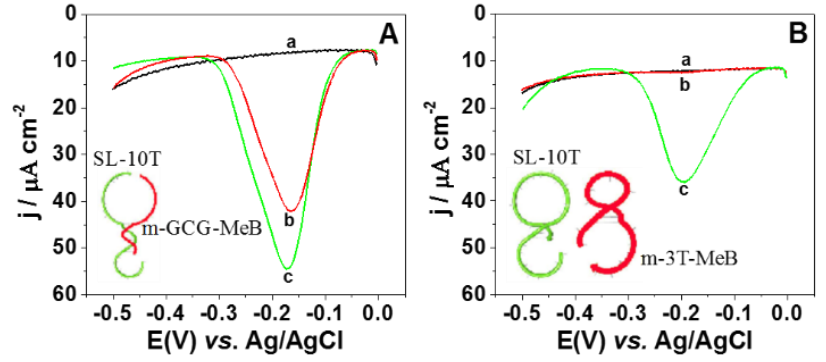

Figure 4: Current densities (a) after immobilization of the DNA-SL probe and 6-mercapto-1-hexanol (b) incubation with adaptor strands ( $m$ and $f$ ) and (c) incubation with $m, f$ and target. Insets are computational modeling using NUPACK for $\boldsymbol{A}) \mathrm{m}$ GCG-MeB and B) $m-3 T-M e B$.

The concentration of the DNA-SL probe during immobilization on the electrode's surface was optimized and analyzed upon hybridization. Fig. 5A shows that the current density maximized at a probe concentration of $0.1 \mu \mathrm{M}$, resulting in a surface density of $2.72 \times 10^{11}$ molecules $/ \mathrm{cm}^{2}$. Furthermore, the concentrations of $m$ and $f 1$ adaptor strands were varied simultaneously in equimolar concentrations $(0.10,0.25,0.50,0.75,1.0 \mu \mathrm{M})$. As seen in Fig. 5B, the current density increases as the concentrations of adaptor strands (m-10T-MeB and f1) increase, reaching a maximum at $0.75 \mu \mathrm{M}$.
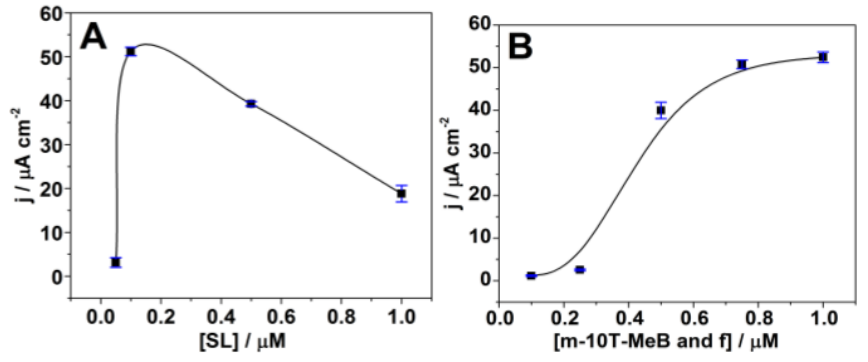

Figure 5: A) Concentration dependence of DNA-SL probe (1 $\mu M \mathrm{~m}$-10T-MeB, f1, and miRNA-122) and $B$ ) adaptor strands (m-10T-MeB and f1, at 0.1 $\mu \mathrm{M}$ DNA-SL probe).

Sensor selectivity was studied with a target containing a SNS (see sequences in Table 1). As observed, the current density was negligible (Fig. 6 left-c) when compared to the fully matched target at the same concentration (50 nM; Fig. 6 left-b). Furthermore, even when the target containing a SNS was used in four-fold excess $(200 \mathrm{nM})$ the current density remained negligible (Fig. 6 left-d), thus reflecting the capability of the $4 \mathrm{~J} \mathrm{E-biosensor} \mathrm{to} \mathrm{detect} \mathrm{a} \mathrm{fully}$ matched target even in excess amount of a single base mismatched nucleic acid, a property important in practice. ${ }^{55}$ It is also worst notice to highlight that the $\mathrm{m}$ strand by itself along with the target does not hybridize as zero signal is observed as shown in Fig. 6 right (blue line).
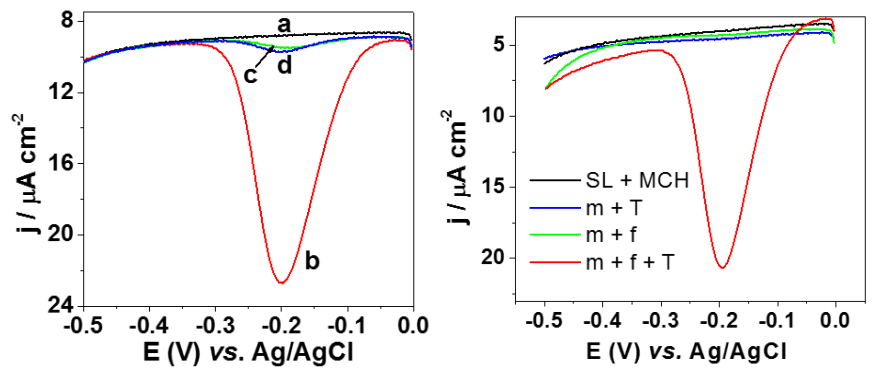

Figure 6: Left. 4J E-biosensor response for a) DNA-SL probe, b) $50 \mathrm{nM}$ target, and c) $50 \mathrm{nM}$ and d) $200 \mathrm{nM}$ of target containing a SNS, and Right. Strands interaction.

Sensor regeneration. It is known that DNA-based sensors comprised of a linear probe and a fully matched target can be regenerated by the addition of external stress, such as heating the duplex hybrid to its respective melting temperature, or by changing $\mathrm{pH}$ to drastic conditions [50]. In contrast, Lubin et al. [58] reported the regeneration of a signal OFF DNA$S L$ probe sensor by rinsing with water for $30 \mathrm{~s}$. This is most likely due to the DNA-SL probe configuration, which thermodynamically favors a hairpin configuration vs. the duplex hybrid. Similarly, the $4 \mathrm{~J}$ structure has been shown to dissociate at room temperature after rinsing with water. This dissociation indicates a unique instability of the $4 \mathrm{~J}$ complex in the absence of ions, most likely $\mathrm{Mg}^{2+}$, which are known to provide stability to DNA 4J structures. [59] Thus, the 4J E-biosensor was reused up to 7 times after the original hybridization with over $97 \%$ recovery (Fig. 7 ). 


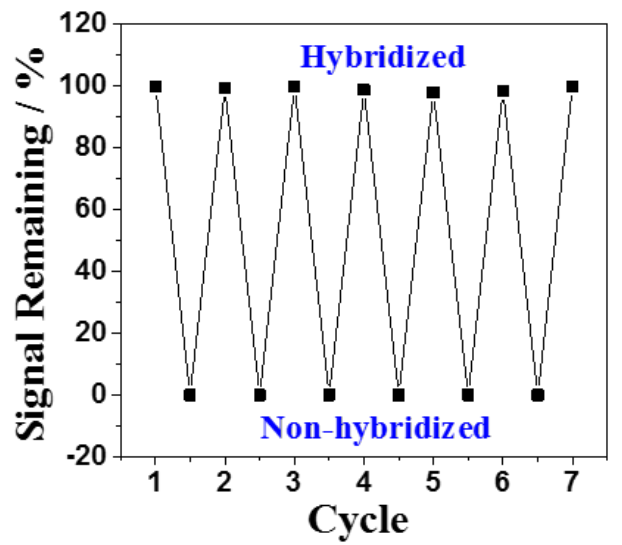

Figure 7: Regeneration of the 4J E-biosensor.
Sensor response. Since the 4J E-biosensor was able to withstand regeneration, calibration curves were performed using the same sensor (Fig. 8). Follow each hybridization event, the sensor was rinsed for $30 \mathrm{~s}$. with water and used for the next target concentration. The current density increased with increasing concentrations of miRNA-122 from 5 to $75 \mathrm{nM}$ as shown in Figure 9A. The linear dynamic range (LDR) was from 5 to $50 \mathrm{nM}$ and the response became nonlinear beyond the upper level, indicating sensor saturation. The limit of detection (LOD) was calculated to be $3.2 \mathrm{nM}$.
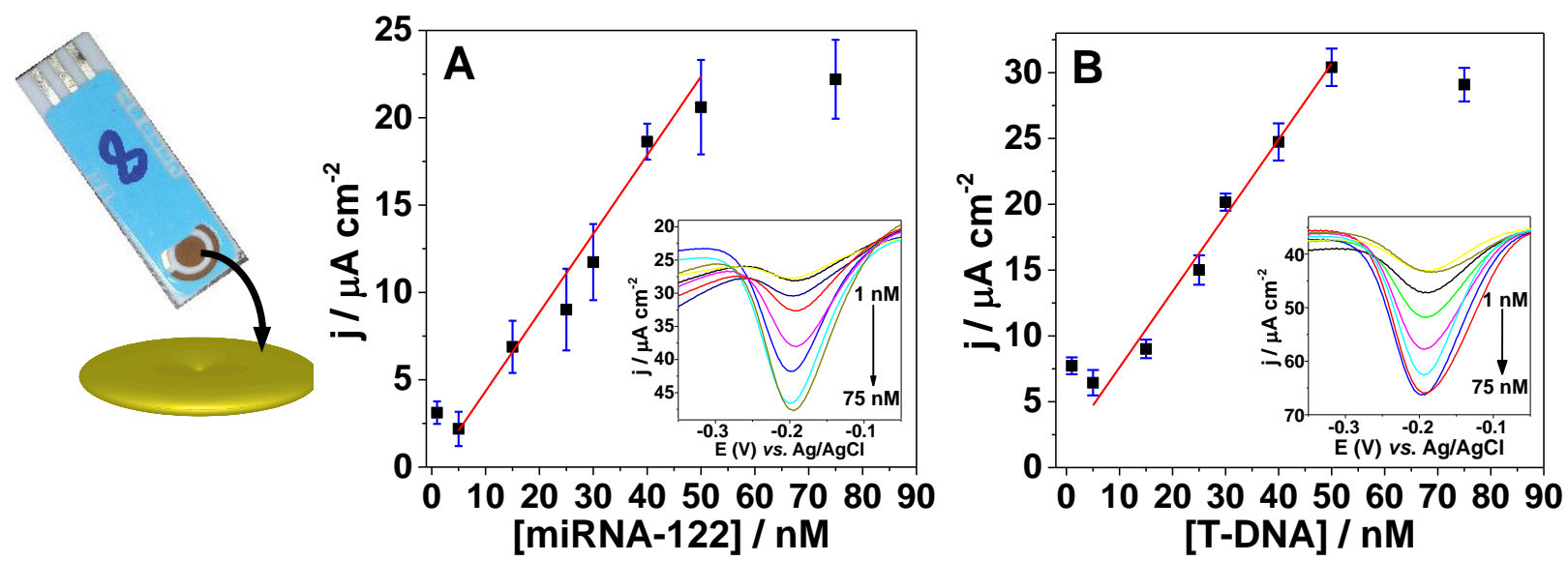

Figure 8: A) Calibration curve for miRNA-122 and B) T-DNA. Inset: SWVs for 1, 5, 15, 25, 30, 40, 50, and 75 $n M$, in $H B$ from 0 to $-0.5 \mathrm{~V}$.

The target-binding arms of the adaptor strands $\mathrm{m}$ and $f$ can be changed to tailor the sensor to each new target sequence using one optimized DNA-SL probe, providing a unique universal sensing platform. The sensor was incubated with a target DNA (T-DNA) sequence using the same DNA-SL probe to investigate the ability to detect other nucleic acids along with adaptor strands m-10T-MeB and $\mathrm{f} 2$ (sequences in Table 1). As seen in Fig. 9B, the current density increased with increasing concentrations of T-DNA from 5 to $75 \mathrm{nM}$. The LDR was from 5 to $50 \mathrm{nM}$ and the response became nonlinear beyond the upper level. The LOD was calculated to be $500 \mathrm{pM}$.

\section{Conclusions}

Here it was demonstrated that the 4J E-biosensor was successfully used for RNA and T-DNA detection using the same DNA-SL as a universal probe. Regeneration of the sensor was possible with simple rinse with water. Multiple analytes can be detected with one single probe, increasing the potentability for commercialization.

\section{Acknowledgements}

The authors acknowledge NSF-nanobiosensing grant number \#1706802 and Florida Health Department grant \# 7ZK05, the College of Sciences and the Department of Chemistry at the University of Central Florida for financial support of this research. DMK was supported by NSF CCF grants $\# 1117205$ and 1423219 and $\mathrm{NIH}$ R15Al10388001A1.

\section{References}

[1] World Health Organization, F. Global tuberculosis report 2014.

[2] R. F. O. Franca, C. C. da Silva, S. O. De Paula, Recent advances in molecular medicine techniques for the diagnosis, prevention, and control of infectious diseases European Journal of Clinical Microbiology \& Infectious Diseases, 32 (2013) 723-728. 
[3] P. Yager, G.J Domingo, J. Gerdes, in Annual Review of Biomedical Engineering, 2008, vol. 10, pp. 107-144.

[4] M. L. Y. Sin, K. E. Mach, P. K. Wong, J. C. Liao, Advances and challenges in biosensor-based diagnosis of infectious diseases Expert Review of Molecular Diagnostics 14 (2014) 225-244.

[5] S. A. Kushon, J. P. Jordan, J. L. Seifert, H. Nielsen, P. E. Nielsen, B. A. Armitage, Effect of secondary structure on the thermodynamics and kinetics of PNA hybridization to DNA hairpins $J$ Am Chem Soc 123 (2001) 10805-10813.

[6] J.C.Tan, J. J. Patel, A. Tan, J. C. Blain, T. J. Albert, N. F. Lobo, M. T. Ferdig, Optimizing comparative genomic hybridization probes for genotyping and SNP detection in Plasmodium falciparum Genomics 93 (2009) 543-550.

[7] Armitage, B. A. The impact of nucleic acid secondary structure on PNA hybridization Drug Discov Today 8 (2003) 222-228.

[8] V. Gubala, L. F. Harris, A. J. Ricco, M. X. Tan, D. E. Williams, Point of Care Diagnostics: Status and Future Analytical Chemistry 84 (2012) 487-515.

[9] A. Niemz, T. M. Ferguson, D. S. Boyle, Point-of-care nucleic acid testing for infectious diseases Trends in Biotechnology 29 (2011) 240-250.

[10] M. R. Hartman, R. C. H. Ruiz, S. Hamada, C. Y. Xu, K. G. Yancey, Y. Yu, W. Han, D. Luo, Point-of-care nucleic acid detection using nanotechnology Nanoscale 5 (2013) 10141-10154.

[11] D. M. Kolpashchikov, Binary Probes for Nucleic Acid Analysis Chem Rev 110 (2010) 4709-4723.

[12] D. M. Kolpashchikov, A binary DNA probe for highly specific nucleic acid recognition $J$ Am Chem Soc 128 (2006) 10625-10628.

[13] Y. V. Gerasimova, D. M. Kolpashchikov, Detection of bacterial 16S rRNA using a molecular beacon-based $X$ sensor Biosens. Bioelectron. 41 (2013) 386-390.

[14] Y. V. Gerasimova, D. M. Kolpashchikov, Folding of $16 S$ rRNA in a Signal-Producing Structure for the Detection of Bacteria Angewandte Chemie-International Edition, 52 (2013) 10586-10588.

[15] Y. V. Gerasimova, E. M. Cornett, E. Edwards, X. L. Su, K. H. Rohde, D. M. Kolpashchikov, Deoxyribozyme Cascade for Visual Detection of Bacterial RNA Chembiochem, 14 (2013) 2087-2090.
[16] R. Abraham, T. Chonmaitree, J. McCombs, B. Prabhakar, P. T. Loverde, P. L. Ogra, Rapid detection of poliovirus by reverse transcription and polymerase chain amplification - application for differentiation between poliovirus and nonpoliovirus enteroviruses Journal of Clinical Microbiology 31 (1993) 395-399.

[17] G. Bonnet, S. Tyagi, A. Libchaber, F. R. Kramer, Thermodynamic basis of the enhanced specificity of structured DNA probes $P$ Natl Acad Sci USA 96 (1999), 6171-6176.

[18] S. A. E. Marras, F. R. Kramer, S. Tyagi, Multiplex detection of single-nucleotide variations using molecular beacons Genet Anal-Biomol E. 14 (1999) 151-156.

[19] S. Tyagi, D. P. Bratu, F. R. Kramer, Multicolor molecular beacons for allele discrimination Nat Biotechnol. 16 (1998) 4953.

[20] S. Tyagi, F. R. Kramer, Molecular beacons: Probes that fluoresce upon hybridization Nat Biotechnol. 14 (1996) 303-308.

[21] C. H. Fan, K. W. Plaxco, A. J. Heeger, Electrochemical interrogation of conformational changes as a reagentless method for the sequence-specific detection of DNA P Natl Acad Sci USA 100 (2003) 9134-9137.

[22] G. V. Guerreiro, A. J. Zaitouna, R. Y. Lai, Characterization of an electrochemical mercury sensor using alternating current, cyclic, square wave and differential pulse voltammetry Anal Chim Acta. 810 (2014) 79-85.

[23] W. W. Yang, R. Y. Lai, Comparison of the Stem-Loop and Linear Probe-Based Electrochemical DNA Sensors by Alternating Current Voltammetry and Cyclic Voltammetry Langmuir. 27 (2011) 1466914677.

[24] C. Yang, B. Dou, K. Shi, Y. Chai, Y. Xiang, R. Yuan, Multiplexed and Amplified Electronic Sensor for the Detection of MicroRNAs from Cancer Cells Analytical Chemistry. 86 (2014) 11913-11918.

[25] C. E. Immoos, S. J. Lee, M. W. Grinstaff, DNA-PEG-DNA triblock macromolecules for reagentless DNA detection J Am Chem Soc. 126 (2004) 10814-10815.

[26] Y. Xiao, A. A. Lubin, B. R. Baker, K. W. Plaxco, A. J. Heeger, Single-step electronic detection of femtomolar DNA by targetinduced strand displacement in an 
electrode-bound duplex $P$ Natl Acad Sci USA 103 (2006)16677-16680.

[27] E. Farjami, L. Clima, K. Gothelf, E. E. Ferapontova, "Off On" Electrochemical Hairpin-DNA-Based Genosensor for Cancer Diagnostics Anal Chem. 83 (2011) 1594-1602.

[28] S. Liu, W. Su, Z. Li, X. Ding, Electrochemical detection of lung cancer specific microRNAs using 3D DNA origami nanostructures Biosensors \& Bioelectronics. 71 (2015) 57-61.

[29] Wu, Y.; Lai, R. Y. Effects of DNA Probe and Target Flexibility on the Performance of a "Signal-on" Electrochemical DNA Sensor Analytical Chemistry, 2014, 86, 8888-8895.

[30] H. Yin, Y. Zhou, Chen, C.; Zhu, L.; Ai, S. An electrochemical signal 'off-on' sensing platform for microRNA detection Analyst. 137 (2012) 1389-1395.

[31] J. Grimes, Y. V. Gerasimova, D. M. Kolpashchikov, Real-Time SNP Analysis in Secondary-Structure-Folded Nucleic Acids Angewandte Chemie International Edition. 49 (2010) 8950-8953.

[32] W. Li, P. Wu, H. Zhang, C. X. Cai, Catalytic signal amplification of gold nanoparticles combining with conformation-switched hairpin DNA probe for hepatitis $C$ virus quantification Chem Commun. 48 (2012) 7877-7879.

[33] S. Rodriguez-Mozaz, M. J. L. de Alda, M. P. Marco, D. Barcelo, Biosensors for environmental monitoring - A global perspective Talanta 65 (2005) 291-297.

[34] P. Yanez-Sedeno, L. Aguei, R. Villalonga, J. M. Pingarron,Biosensors in forensic analysis. A review Anal Chim Acta. 823 (2014) 1-19.

[35] A. M. Krichevsky, K. S. King, C. P. Donahue, K. Khrapko, K. S. A. Kosik, microRNA array reveals extensive regulation of microRNAs during brain development Rna-a Publication of the Rna Society. 9 (2003) 1274-1281.

[36] E. Varallyay, J. Burgyan, Z. Havelda, MicroRNA detection by northern blotting using locked nucleic acid probes Nature Protocols. 3 (2008) 190-196.

[37] C. G. Kevil, L. Walsh, F. S. Laroux, T. Kalogeris, M. B. Grisham, J. S. Alexander, An improved, rapid Northern protocol Biochem Biophys Res Commun. 238 (1997) 277-279.

[38] E. M. Southern, Detection of Specific Sequences among DNA Fragments
Separated by Gel-Electrophoresis Journal of Molecular Biology. 98 (1975) 503-517.

[39] C. M. Hindson, J. R. Chevillet, H. A. Briggs, E. N. Gallichotte, I. K. Ruf, B. J. Hindson, R. L. Vessella, M. Tewari, Absolute quantification by droplet digital PCR versus analog real-time PCR Nat Methods, 10 (2013) 1003-1005.

[40] K. Rekker, M. Saare, A. M. Roost, A.-L. Kubo, N. Zarovni, A. Chiesi, A. Salumets, Peters, M. Comparison of serum exosome isolation methods for microRNA profiling Clinical Biochemistry. 47 (2014) 135-138.

[41] T. D. Schmittgen, J. M. Jiang, Q. Liu, L. Q. Yang, A high-throughput method to monitor the expression of microRNA precursors Nucleic Acids Research. 32 (2004) 1-10.

[42] S. A. E. Marras, S. Tyagi, F. R. Kramer, Real-time assays with molecular beacons and other fluorescent nucleic acid hybridization probes Clin Chim Acta. 363 (2006) 48-60.

[43] S. Elsayed, K. Plewes, D. Church, B. Chow, K. Y. Zhang, Use of molecular beacon probes for real-time PCR detection of Plasmodium falciparum and other Plasmodium species in peripheral blood specimens Journal of Clinical Microbiology, 44 (2006) 622-624.

[44] H. T. Allawi, J. E. Dahlberg, S. Olson, E. Lund, M. Olson, W. P. Ma, T. Takova, B. P. Neri, V. I. Lyamichev, Quantitation of microRNAs using a modified Invader assay RNA. 10 (2004) 1153-1161.

[45] X. Gong, W. Zhou, D. Li, Y. Chai, Y. Xiang, R. Yuan, RNA-regulated molecular tweezers for sensitive fluorescent detection of microRNA from cancer cells Biosensors \& Bioelectronics. 71 (2015) 98-102.

[46] Q. Xi, D.-M. Zhou, Y.-Y. Kan, J. Ge, Z.-K. Wu, R.-Q. Yu, J.-H. Jiang, Highly Sensitive and Selective Strategy for MicroRNA Detection Based on WS2 Nanosheet Mediated Fluorescence Quenching and Duplex-Specific Nuclease Signal Amplification Analytical Chemistry. 86 (2014) 1361-1365.

[47] X. Zhu, Y. Shen, J. Cao, L. Yin, F. Ban, Y. Shu, G. Li,Detection of microRNA SNPs with ultrahigh specificity by using reduced graphene oxide-assisted rolling circle amplification Chem Commun. 51 (2015) 10002-10005.

[48] R. Y. Lai, K. W. Plaxco, A. J. Heeger, Aptamer-based electrochemical detection of picomolar platelet-derived growth factor 
directly in blood serum Analytical Chemistry. 79 (2007) 229-233.

[49] G. Lai, F. Yan, H. Ju, Dual Signal Amplification of Glucose OxidaseFunctionalized Nanocomposites as a Trace Label for Ultrasensitive Simultaneous Multiplexed Electrochemical Detection of Tumor Markers Analytical Chemistry. 81 (2009) 9730-9736.

[50] F. Li, J. Peng, Q. Zheng, X. Guo, H. Tang, S. Yao, Carbon Nanotube-Polyamidoamine Dendrimer Hybrid-Modified Electrodes for Highly Sensitive Electrochemical Detection of MicroRNA24 Analytical Chemistry. 87 (2015) 4806-4813.

[51] X. Y. Wu, Y. Q. Chai, P. Zhang, R. Yuan. An Electrochemical Biosensor for Sensitive Detection of MicroRNA-155: Combining Target Recycling with Cascade Catalysis for Signal Amplification Acs Appl Mater Inter. 7 (2015) 713-720.

[52] A. A. Lubin, B. V. S. Hunt, R. J. White, K. W. Plaxco. Effects of Probe Length, Probe Geometry, and Redox-Tag Placement on the Performance of the Electrochemical EDNA Sensor Anal Chem. 81 (2009) 21502158.

[53] S. S. W. Yeung, T. M. H. Lee, I. M. Hsing, Electrochemical real-time polymerase chain reaction J Am Chem Soc. 128 (2006) 13374-13375.

[54] A. J. Bergren, R. L. McCreery, Analytical Chemistry in Molecular Electronics Annu Rev Anal Chem. 4 (2011) 173-195.

[55] F. Diehl, K. Schmidt, M. A. Choti, K. Romans, S. Goodman, M. Li, K. Thornton, N. Agrawal, L. Sokoll, S. A. Szabo, K. W. Kinzler, B. Vogelstein, L. A., Jr. Diaz, Circulating mutant DNA to assess tumor dynamics Nature Medicine. 14 (2008) 985990.
[56] G. Gupta, P. Atanassov, Electrochemical DNA Hybridization Assay: Enzyme-Labeled Detection of Mutation in p53 Gene Electroanal. 23 (2011) 1615-1622.

[57] T. M. Herne, M. J. Tarlov, Characterization of DNA Probes Immobilized on Gold Surfaces J Am Chem Soc. 119 (1997) 8916-8920.

[58] A. A. Lubin, R. Y. Lai, B. R. Baker, A. J. Heeger, K. W. Plaxco, Sequence-specific, electronic detection of oligonucleotides in blood, soil, and foodstuffs with the reagentless, reusable E-DNA sensor Anal Chem. 78 (2006) 5671-5677.

[59] D. M. J. Lilley, Structures of helical junctions in nucleic acids Quarterly Reviews of Biophysics. 33 (2000) 109-159.

E-mails: karin.chumbimunitorres@ucf.edu, dmitry.kolpashchikov@ucf.edu 